Vol. 1. No. 1, 1993

\title{
CARBON-13 NMR OF SOME S-METHYLTHIOLESTERS
}

\author{
Paulo Irajara Borba Carneiro* \\ Instituto de Química \\ Universidade Federal do Parana - UFPR \\ Caixa Postal 19081 \\ 81.521-970 Curitiba, Paranä, BRASIL \\ $\&$ \\ Roberto Rittner and Rogērio Custödio \\ Instituto de Química \\ Universidade Estadual de Campinas - UNICAMP \\ Caixa Postal 6154 \\ 13.081-970 Campinas, São Paulo, BRASIL
}

\begin{abstract}
H-1 and C-13 NMR chemical shifts for some alky1-S-methy1thiolesters ( $R C O S M e$ ) are reported. The $\alpha$-methylene and carbonyl carbons show lower field shifts when compared to analogous carboxylic acid derivatives. This behavior was explained by using charge densities and separation energies calculated by the AMI MO-SCF semiempirical method.

KEYWORDS: C-13 NMR, Chemical Shifts, Alkyl-S-methylthiolesters.

\section{RESUMO}

o presente trabalho apresenta deslocamentos quimicos de RMN de H-1 e C-13 para alguns ésteres de alquil-s-metiltiol (RCoSMe). Os carbonos do grupo $\alpha$-metileno e carbonila exibem um deslocamento para campo mais baixo, quando comparados com derivados análogos de ácidos carboxílicos. Este comportamento foi explicado usando densidades de carga e energias de separaça calculadas através do método semi-empirico AM1 MO-SCF.
\end{abstract}

\section{INTRODUCTION}

Although thiolesters (RCOSMe) are important starting materials for condensation and transference reactions of the acyl group in biological systems ${ }^{1}$, there is a lack of NMR data in the literature for thisitype of compounds, particularly when $R$ is a nonbranched alkyl group. The electronic structure of these compounds is well known.

C-13 NMR chemical shifts for the $\alpha$-methylene and carbonyl carbons have been reported to show a lower field chemical shift in relation to analogous carboxylic acid derivatives. This work describes the study of a closely related series of four alkyl-s-methylthiolesters that has also been investigated using the semiempirical AMl MO-SCF calculations in order to check the generality of the observed behavior.

* Author to whom correspondence should be addressed. 


\section{EXPERIMENTAL PROCEDURE}

Materials.

Solvente were of spectroscopic quality and were used without further purification. All compounds were prepared according to procedures described in the literature 9,10 .

spectra.

The C-13 NMR spectra of $1,0 \mathrm{M}$ solutions in $\mathrm{CHCl}_{3}$, with $5 \%$ TMS as an internal reference in $10 \mathrm{~mm} 0 . \mathrm{d}$. sample tubes, were recorded at $25,2 \mathrm{MHz}$ using a Varian $\mathrm{XL}-100$ spectrometer in the FT mode. The conditions were as follows: pulse width, $20 \mu s$; acquisition time, $0,67 \mathrm{~s}$; spectral width, $6150 \mathrm{~Hz}$; pulse repetition time, $0,4 \mathrm{~s}$; temperature, $300^{\circ} \mathrm{C}$; internal lock, $\mathrm{D}_{2} 0$; angle tumbling, 45\%; number of transients, 6000 ; and number of data points, 8192. The C-13 NMR spectra were recorded in both the proton-noise decoupled and coupled modes. The $\mathrm{H}-1$ NMR spectra of the various solutions investigated, in $5 \mathrm{~mm}$ $0 . d$. sample tubes, were recorded at $80 \mathrm{MHz}$ using a Bruker Aw-80 spectrometer in the FT mode.

\section{Computations.}

Net charge densities and energy separations were obtained through the AMI SCF-MO semiempirical method on an IBM computer with the AMPAC program.

\section{RRSULTS AND DRSCUSBION}

Table I summarizes the experimental $c-13$ chemical shifts obtained for the four alkyl-s-methylthiolesters studied.

TABLE I. C-13 NMR CHEMICAL SHIFTS ${ }^{a}$ FOR ALKYL-S-METHYLTHIOLESTERS ${ }^{b}$.

$$
\mathrm{R}^{2} \mathrm{CH}_{2}{ }_{\mathrm{COSMO}}^{\mathrm{C}}
$$

\begin{tabular}{|c|c|c|c|c|c|c|c|c|}
\hline \multicolumn{2}{|c|}{ compounds } & $\approx-1$ & $c-2$ & $a-3$ & $c-4$ & $6-5$ & $\overline{c-b}$ & $\check{\sim}-1$ \\
\hline$\underline{1}$ & $\mathrm{CH}_{3} \mathrm{CH}_{2} \mathrm{COSM}_{6}$ & 198.1 & $3 E .5$ & 9. 1 & & & & 10.7 \\
\hline$\underline{\varepsilon}$ & $\mathrm{CH}_{3} \mathrm{CH}_{2} \mathrm{CH}_{2} \mathrm{COSMO}_{0}$ & 198.5 & 44.6 & 18.3 & 12.4 & & & 10.0 \\
\hline 3 & $\mathrm{CH}_{3} \mathrm{CH}_{2} \mathrm{CH}_{2} \mathrm{CH}_{2} \mathrm{COSMo}$ & 197.0 & 42.8 & 27.1 & 21.5 & 13.0 & & 10.5 \\
\hline 4 & $\mathrm{CH}_{3} \mathrm{CH}_{2} \mathrm{CH}_{2} \mathrm{CH}_{2} \mathrm{CH}_{2}$ Cosmo & 198.1 & $43 . \Xi$ & 24.9 & 30.7 & 21.9 & $13 . \Xi$ & 10.8 \\
\hline
\end{tabular}

$\therefore$ in ppon rolativo to TMS. b: Rer. 6 in $\mathrm{HCCl}_{3}$ solutions. 
Table II presents the boiling points and experimental H-1 NMR data obtained. The physical constants of compounds $1-4$ agree with data published in the literature ${ }^{1-4}$.

TABLE II. PHYSICAL AND SPECTRAL DATA FOR ALKYL-S-METHYLTHIOLESTERS ${ }^{a}$.

\begin{tabular}{|c|c|c|c|c|c|c|c|}
\hline Compound & bp $\left({ }^{\circ}\right.$ (c) Torr) & $H-z^{b}$ & $H-3$ & $\mathrm{H}-4$ & $H-5$ & $H-6$ & $\mathrm{H}-1$ \\
\hline$\underline{1}$ & $60 / 110$ & $2.60^{\circ}$ & $1.20^{t}$ & & & & 2. $30^{\circ}$ \\
\hline$\underline{a}$ & $55 / 40$ & $2.50^{\circ}$ & $1.70^{\circ t}$ & $0.95^{t}$ & & & $2.25^{\circ}$ \\
\hline 3 & 70,30 & $2.55^{t}$ & $1 \cdot 10-1$ & $.80^{\mathrm{m}}$ & $0.80^{t}$ & & 2. $25^{3}$ \\
\hline 4 & $70 / 20$ & $2.50^{\prime}$ & $1.65^{m}$ & 1. $10-1$ & $.45^{m}$ & $0.90^{t}$ & $2.25^{3}$ \\
\hline
\end{tabular}

a: ppm rolative to IMS. in deuterated chloroform solutions. b: $s=$ singlet; $t=t r i p l e t ; q-$ quartot; $s t=$ soxtot and $m-$ multiplet

The signals of these compounds were assigned by singlefrequency off-resonance decoupling (SFOR.D), proton noise decoupled (DFL) spectra and known chemical shift rules ${ }^{5}$.

The chemical shifts of the carbonyl carbon were found in the $197,30+0,80$ ppm band, next to analogous aldehydes and ketones. This values is about $15-20 \mathrm{ppm}$ higher, when compared to analogous carboxylic acid derivatives.

In the alky1-s-methylthiolesters

$$
\left(\begin{array}{ccc}
2 & 2 & 2 \\
R- & -\mathrm{CH}_{2} & \cos \mathrm{M}_{\theta}
\end{array}\right] \text {, }
$$$$
\mathrm{C}-1 \text { and }
$$

C-2 show paramagnetic chemical shifts. On the other hand, the $\mathrm{C}-1$ ' carbon showed diamagnetic chemical shifts, when compared to analogous carboxylic acid derivatives.

Comparison between the thiolesters and analogous carboxylic acid derivatives showed that the $\mathrm{C}-0$ bond length is shorter than the $\mathrm{C}-\mathrm{S}$ bond. This is the case because the oxygen atom is more electronegative than the sulfur atom. The magnitude of the p $\pi-p \pi$ or $p \pi-d \pi$ conjugation is inversely proportional to the core length and is more pronounced in the $\mathrm{C}-0$ bond. This reduces the carbonyl withdrawing effect in the alpha carbon. In the oxygenated esters the carbonyl carbon is more shielded than in the thiolesters analogues.

The inductive effect of the oxygen atom deshields the methyl carbon $\left(\mathrm{C}-\mathrm{l}^{\prime}\right)$ and its resonance appears in a lower field. The chemical shift differences between these compounds is thus caused by the differences in size between the two heteroatoms and the differences in their electronegativities, polarizabilities and energy of the atomic lone pair orbitals? 
Making use of the AMl MO-SCF semiempirical calculations, we computed the charge densities of the carbon atoms in compounds $\underline{5}$ and $\underline{6}$ and also determined the energy separation $(\Delta E)$.

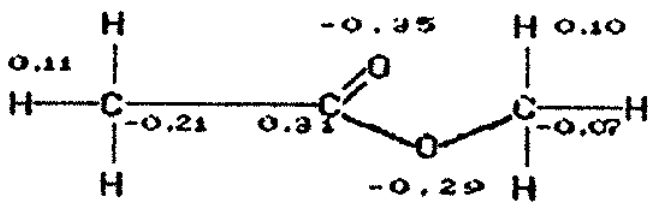

$\underline{5}$<smiles>O=C(O)SSC(=O)O</smiles>

$\underline{6}$

According to Equation (I) the paramagnetic constant, derived by Karplus and Pople 8 , shows that the higher $\triangle E$ and $Q_{i}$, the higher the shielding observed in the carbon atom. our experimental $r \in s u l t s$ and the values computed for $\triangle E$ and $Q_{i}$ are in agreement with these observations.

$$
\sigma_{p}-\frac{\theta^{2} h^{2}}{m^{2} c^{2}} \Delta E^{-1}\left\langle r^{-\infty}\right\rangle_{2 p}\left[Q_{1}+\sum Q_{n}\right]
$$

The charge densities show that in the methyl ester $(\mathrm{C}-1)$ the carbonyl carbon is more shielded $\left(0_{\mathrm{C}-1}=0,31\right)$ than in the thiolester analogue $\left(Q_{C-1}=0,10\right)$.

Dur calculations show that that the energy separation and charge of the C-1 of the thiolester are smaller. This corresponds to higher polarizability and chemical shifts of the alpha and carbonyl carbons of these sompounds.

These observations can explain the principal properties of the thiolesters: $\mathrm{C}-1$ and $\mathrm{C}-2$ have resonance in a lower field when compared to analogous oxygenated esters $\left(\mathrm{c}-1 \Delta \delta_{1} 15-20 \mathrm{ppm}\right.$, $\left.c-2 \Delta \delta_{\approx 10} \mathrm{ppm}\right)$. They also expalin the higher reactivity of thiolacetates to alkaline hydrolysis when compared to analogous acetates ${ }^{2}$. The lower electronegativity of the sulfur atom results in a lower inductive effect in $\mathrm{C}-1^{\prime}$. In fact, $\mathrm{C}-1^{\prime}$ ' is more shielded in these compounds in the $C-13$ NMR spectra. C-1' appears in an even higher field $(\Delta \delta \approx 40 \mathrm{ppm})$ when compared to alkyl esters analogues.

These observations are confirmed by the chemical shifts of s-methylethanethioate and methyl acetate shown on iotra following page. 


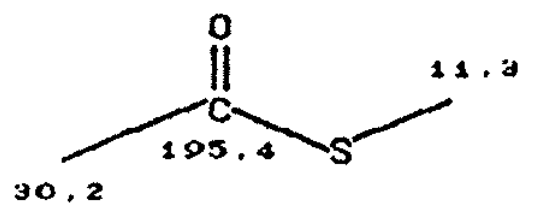

30,2

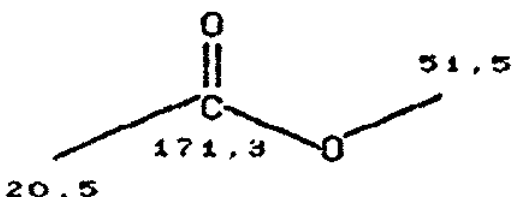

20,5

Acknowledgements. The authors thank the Conselho Nacional de Desenvolvimento Cientifico e Tecnologico (CNPq) for financial support of this research and for a grant to R.R and R.C., and Coordenação e Aperfeiçoamento de Pessoal de Nivel Superior (CAPES) for a grant to P.I.B.C.

\section{REFRRENCES}

1. C. M. Hall and J. Wemple, J. Org. Chem., 42,2118-2123 (1977).

2. J. P. Idoux, P. T. R. Hwang and C. K. Hancock, J. Org. Chem., $38,4239-4243$ (1973).

3. J. Obermeyer, Ber., 20, 2918-2928 (1887).

4. V. A. Vinkurov and E. G. Gaevoi, J. Org. Chem. USSR, 23, 1990-1991 (1987).

5. E. Breitmeier and W. Voelter, "Carbon-23 NMR Spectroscopy", 3 rd edition, Weinheim, New York, USA, 1987.

6. P. I. B. Carneiro, "Tese de Doutoramento", UNICAMP, Campinas, São Paulo, 1991 .

7. F. Bernardi,I:G. Csizmadia, H. B. Schlegel and S. Wolfe, Can. J. Chem., 53, 1144-1153 (1975).

8. M. Karplus and J. A. Pople, J. Chem. Phys., 38, 2803 (1963).

9. D. J. Dagli, P. S. Yu and J. Wemple, J. Org. Chem., 40, 3173-3178 (1975).

10. P. N. Rylander and S. Tarbell, J.Amer. Chem. Soc., 72, 3021-3025 (1950). 